\title{
Effectiveness of music therapy on anxiety level, and pain perception in primipara mothers during first stage of labor in selected hospitals of Odisha
}

\author{
Debajani Nayak $^{1}$, Sharada Rastogi ${ }^{2}$, Om Kumari Kathuria ${ }^{3}$ \\ ${ }^{1}$ Lecturer, Department of Obstetrics and Gynaecological Nursing, SUM Nursing College, \\ Siksha 'O' Anusandhan University, Bhubaneswar, 751003, Odisha, India \\ ${ }^{2}$ Senior tutor, R.A.K. College of Nursing, New Delhi, 100024, India \\ ${ }^{3}$ Ex-senior lecturer, R.A.K. College of Nursing, New Delhi, 100024, India
}

\begin{abstract}
Labour pain is one of the most severe forms of pain that each woman experience during child birth period. Anxiety and pain are closely interrelated with each other. The interaction between anxiety and pain may become a spiralling process. Pain and anxiety together can eventually become severe, in turn, a cause for panic and resulting maternal and fetal complications. In this study the level of anxiety and pain perception in primipara mothers during the first stage of labour after receiving music therapy have been assessed. The study was a quasi experimental research approach with one group pre-test post-test design. The sample comprised of 30 primipara mothers and was purposively selected. Mean post-test (50.06) and pre-test (59.23) anxiety scores differed significantly from each other in the experimental group. Similar trend was followed in case of pain perception scores (posttest score 6.27; pretest score 7.8). Further, a significant correlation $(r=0.8192)$ was obtained between anxiety and level of pain perception scores. Findings of the study revealed that music therapy would be very helpful in alleviating anxiety level and pain perception in primipara mothers during first stage of labour.
\end{abstract}

Key Words: Anxiety, Labor, Music therapy, Pain perception, Primipara

\section{Introduction}

Natural child birth is a unique aspect of association of physiologic processes with pain, discomforts and pleasure. It is a universal human experience; yet the birth experience can be different across cultures. Maternal deaths can occur during the process of labour and delivery or arise from events in labour and delivery. In India, over 10, 0000 women die due to pregnancy related causes every year. National Family Health Survey (NFHS-2) data shows that the maternal mortality ratio (pregnancy related deaths per 1,00,000 births) is 540 which is even worse in rural areas 619 than in urban areas (http://whiteribbonalliance.org/). The birth environment affects a woman's experience of pain and her ability to cope with pain during labour. A fearful woman can become tense, often without her realization. Getting frightened or threatened during labour may adversely affect the child birth process in one way or the other.

Most pain during childbirth results from normal physiologic events [1]. During labour, anxiety and fearfulness in women is usually noticed. Nurses remain in direct and continuous contact with the mothers in labour, and hence play a vital role in pain management. Understanding the nature and effects of pain during the labour process, nurses provide supportive care for physical comfort. Both non-pharmacologic and pharmacologic approach may hold good for pain management during labour. Among the non pharmacologic methods of pain relief, massage, acupuncture and hot application are proved to be effective techniques for management of labour pain [2].

Music is an age old part of Ayurveda, the holistic Indian Science that promotes a happy and healthy lifestyle. Music therapy is a concept that has been existent since ages. It explains how different types and pitches of sounds work on three major energy systems working in our body, which, in Ayurveda, are known as Vat Dosha, Pitta Dosha and Kaph Dosha. Ancient Indian Ragas were designed with rules and regulations to regulate the working of these Doshas at their optimum levels in their functioning time period and thus for the betterment of the health of mankind and women in particular who suffers pain of menstruation, abortion, pregnancy and labour (http://sursanjeevan.com/). Music can touch the mother deeply and may reduce her anxiety, stress and perception of pain. Music therapy assisted labour and delivery may also be included in this category since pregnancy is regarded as a normal part of women's life cycles.

Dr. Swarupa R. Iyer (2009) conducted the project of Garbhankur since the last 4 years. It is a complete holistic care given to pregnant women for better mental and physical development of the baby. It also helps in facilitating normal delivery. Till now, around 500 couples have benefited from this project. Sursanjeevan is another system of music therapy conceived and created by Pandit Shashank Katti, 2009 
(http://sursanjeevan.com/) based on the principles of Ayurveda and modern inventions that were testified by the help of some of the latest developments in applied sciences \& medicines. Music therapy has been a highlyresearched phenomenon throughout the western world since the last 5 decades. There have been tremendous studies \& findings suggesting the deep rooted activity of the music on human physiology, specially the neurohormonal system \& brain. Garbhankur encompasses musical management for the expectant mother \& the foetus in the womb. It facilitates smooth delivery of the baby. Since the first month is known only after missing the period, the music is from the second month of pregnancy to the ninth month. The tenth month of pregnancy is just the phase in waiting for the delivery to occur. This phase starts from the very completion of the 9 th month $\&$ does not follow a long course. The musical management provided in the 9 th month is complete enough to go through the last lap of pregnancy ending in natural process of delivery without any intervention required.

It is also a well-established fact worldwide that the therapeutic music used during pregnancy carry no side effects and is beneficial for both foetus and mother as well. It relieves stress of the expectant mother and improves her physical, psychological, intellectual \& spiritual health to the optimum level, thereby making pregnancy a wonderful and blissful experience (Pandit Shashank Katti, 2009) (http://sursanjeevan.com/) [1]. Therefore, nursing research in this area may further shed light on effective management of pain and anxiety of mothers in labour and may hasten healthy maternal and fetal outcomes.

\section{Problem Statement}

A study to assess and evaluate the effectiveness of music therapy on anxiety level and pain perception in primipara mothers during the first stage of labour in selected hospitals of Odisha.

\section{Objectives}

1. To assess the level of anxiety in primipara mothers during the first stage of labour receiving music therapy.

2. To assess the pain perception in primipara mothers during the first stage of labour receiving music therapy.

3. To determine the relationship between anxiety level and pain perception in primipara mothers during the first stage of labour receiving music therapy.

\section{Research Hypotheses}

$\mathbf{H}_{1}$ - There will be a significant difference between mean pre and post test anxiety scores of primipara mothers during the first stage of labour receiving music therapy as measured by C.D. Speilberger's State Scale of State Trait Anxiety Inventory at 0.05 level of significance.

$\mathbf{H}_{2^{-}}$There will be a significant difference between mean pre and post test pain perception score of primipara mothers during the first stage of labour receiving music therapy as measured by numerical pain intensity scale at 0.05 level of significance.

$\mathbf{H}_{3^{-}}$There will be a significant co-relation between post test anxiety level and pain perception scores of primipara mothers during the first stage of labour receiving music therapy as measured by C.D. Speilberger's State Scale of State Trait Anxiety Inventory and numerical pain intensity scale respectively at 0.05 level of significance.

\section{Material \& Methods}

Research Approach: experimental research approach Research Design: Quasi experimental one group pretest posttest design

The symbolic representation of adopted research design can be represented in Fig 1:

\begin{tabular}{|l|l|l|l|}
\hline GROUP & PRETEST & TREATMENT & POST TEST \\
\hline EM & $\mathrm{OA}_{1}, \mathrm{OP}_{1}$, & $\mathrm{X}$ & $\mathrm{OA}_{2}, \mathrm{OP}_{2}$ \\
\hline
\end{tabular}

Figure 1: Symbolic representation of the research design

The interpretations of the symbols are as follows:

EM = Experimental Group (Receives music therapy)

$\mathrm{OA}_{1}=$ Pretest anxiety score of the experimental group.

$\mathrm{OP}_{1}=$ Pretest pain perception score of the experimental group.

$\mathrm{X}=$ Introduction of treatment i.e. Music therapy.

$\mathrm{OA}_{2}=$ Posttest anxiety scores of the experimental group.

$\mathrm{OP}_{2}=$ Posttest pain perception score of the experimental group.

Variables under study

Independent variable: Music therapy

Dependent Variables:

- Level of pain in terms of pain score in primipara mothers during labour 
- Anxiety level of mother during first stage of labour Extraneous variables:

- Mother's general health status

- Hydration status

- Nutritional status

These extraneous variables were not taken care in presence study.

Setting : : Selected hospitals located in Odisha.

Population : Primipara mothers in first stage of labour.

Sample Size $\quad$ : 30 Primipara mothers in first stage of labour

Sampling Technique : Purposive sampling technique

\section{Data Collection Tools}

1. Structured interview schedule for demographic data to collect background data

2. Structured record analysis proforma to collect data regarding true and active labour pain

3. Speilberger's State Trait Anxiety Inventory (STAI) to assess the anxiety level of mother.

4. Numerical Pain Intensity Scale(NPIS)

\section{Establishment of validity of the tool}

The tools were validated by 11 experts from the field of nursing, obstetrics \& gynecology and, naturopathy. The music CDs also validated by music teachers and obstetrician and in the field of nursing.

\section{Reliability}

The reliability of the structured record analysis proforma for labour assessment, numeric pain intensity scale and structure analysis proforma for maternal foetal outcome were established by inter observer reliability and the percentage agreement was 100 . The reliability of the Speilberger's state trait anxiety inventory was established by using Cronbach alpha method and the reliability was 0.8 . Thus the tools were found to be reliable.

\section{Description of treatment \& Procedure for data collection}

A sample of 30 primipara mothers having first stage of labours of selected hospital who met the sample criteria were purposively selected for the study. Data collection was done in active phase of labour. Mothers were interviewed for sample characteristics data. Record analysis was done for active labour assessment. Pretest anxiety level and pain perception of the primipara mothers in active phase of labour were assessed by using the C.D. Speilberger's state scale of state trait anxiety inventory and numerical pain intensity scale respectively. The relaxing musics were selected for music therapy. These musics were in the form of soft music, devotional music, and instrumental music especially for relaxation. These musics were validated by experts from the field of music, obstetrics and field of nursing. The investigator selected the musics on the basis of available literatures and from own personal experience and got them validated by experts. But while administering music therapy, mother's choice was preferred. The music therapy was administered to the mothers for one hour during active phase of labour through ipod and ear phone. After completion of the music therapy the posttest anxiety level and pain perception scores of the primipara mothers in active phase of labour were again assessed.

\section{Ethical consideration}

Inter personal relationship was established, purposes of the study were explained to the mothers, consent taken and confidentiality was assured. No problem was faced during the data collection period. There was full co-operation from the staff and administration.

\section{Plan for data analysis}

According to the objectives and hypothesis of the study and the opinion of the experts it was planned to organize, tabulate, analyze and interpret the data by using both descriptive and inferential statistics. Paired ' $t$ ' test was carried out to compare pretest and posttest values. To find out the relationship between anxiety and pain level scores we calculated Karl Pearson's correlation coefficient (r).

\section{Section-I}

\section{Results}

\section{Findings related to sample characteristics}

* Among the primipara mothers in first stage of labour who participated in the study majority $(73.3 \%)$ were registered while $26.67 \%$ of mothers were not registered for antenatal care. 
* In age of the mother (43.3\%) were in the age group of $20-25$ years and $(53.3 \%)$ were in the age range of 26-30 years.

* In religion majority of the mothers $(83.3 \%)$ were Hindus.

* As regard to education $(33.3 \%)$ of the mothers were having secondary education

* Occupation of the mothers indicated that half of the mother $(53.3 \%)$ was housewives and $(23.33 \%)$ were in service.

* More of the mothers (70\%) were married since 1-2 years while 20\%were married since 3-4years and only $5 \%$ were married since $>5$ years.

* As regard to monthly income of the family (46.66\%) were in the range of Rupees 10,001 and above per month.

* There was no significant medical and surgical history in all the mothers.

* As regards to obstetrical history all mothers in both the group were primiparous, had period of gestation between 37-40 weeks and no history of abortion.

* From the Previous Information none of the mothers in the study had previously received any information regarding the music therapy.

\section{Section-II}

\section{Findings related to labour assessment of primipara mothers}

Followings are the findings regarding active labour assessment in primipara mothers. The active labour assessment was done by using the structured record analysis proforma.

- More number of the mothers $(66.6 \%)$ had duration of labor less than six hours at the time of admission in the labour room.

- $\quad$ Majority of the mothers $(80 \%)$ had not ruptured their membranes.

- More of the mothers (60\%) had dilatation of cervix between 5-6 cm.

- Regarding cervical effacement more number of mothers $(60 \%)$ of mothers had effacement of cervix between $50-75 \%$.

- Station of the head indicated that majority of mothers $(66.6 \%)$ of mothers had at the level of ischial spine.

- Regarding presentation of the all mothers $(100 \%)$ had cephalic presentation.

- Majority of mothers $(86.6 \%)$ had left occipito-anterior position.

- Majority of the mothers $(86.6 \%)$ had experienced uterine contraction in terms of duration between 3045 seconds.

- Majority of mothers $(76.6 \%)$ had experienced three uterine contractions in terms of frequency in 10 minutes.

\section{Section-III}

1. Findings related to the evaluation of effectiveness of music therapy in terms of anxiety of primipara mothers during the first stage of labour

Evaluation of effectiveness of music therapy in terms of anxiety of primipara mothers during the first stage of labour was carried out. Anxiety was tested by using state scale of Speiberger's State Trait Anxiety Inventory which has total 20 questions. Anxiety was recorded twice i.e. in the active phase of labour before starting and after completion of the music therapy. In order to compare the difference between the means of pretest and post-test anxiety scores of experimental group, ' $t$ ' test was computed. The data is given in table 1 and 2 and graphically represented in Figure 2.

Table 1: Mean, Median, Standard Deviation and Range of Score of the Pretest and Posttest anxiety scores of Primipara mothers in the experimental group

\begin{tabular}{|l|c|c|c|c|c|c|c|c|}
\hline \multirow{2}{*}{ GROUP } & \multicolumn{2}{|c|}{ Mean } & \multicolumn{2}{c|}{ Median } & \multicolumn{2}{c|}{ Standard Deviation } & \multicolumn{2}{c|}{ Range of Score } \\
\cline { 2 - 9 } & Pretest & Posttest & Pretest & Posttest & Pretest & Posttest & Pretest & Posttest \\
\hline $\begin{array}{l}\text { Experimental } \\
\begin{array}{l}\text { Group } \\
(\mathrm{n}=30)\end{array}\end{array}$ & & & & & & & $53-64$ & $41-55$ \\
\hline
\end{tabular}

The maximum possible score is 80 


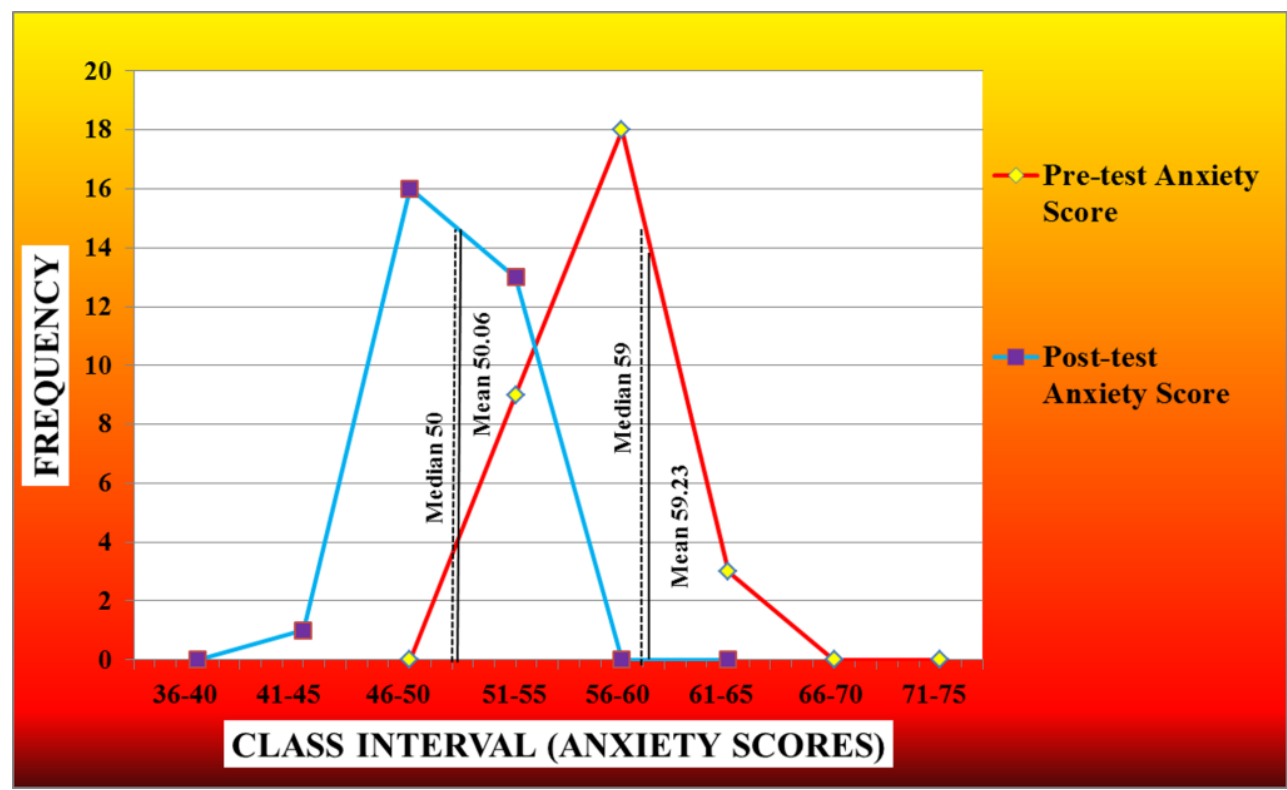

Figure 2: Frequency polygon showing the pre-test and post-test anxiety scores of primipara mothers in the experimental group.

Table-2: Mean, Mean Difference, Standard Deviation Difference, Standard Error of Mean Difference and " $\mathrm{t}$ " values of pre test and post test anxiety scores of Primipara mothers in experimental group

\begin{tabular}{|l|c|c|c|c|c|}
\hline \multicolumn{1}{|c|}{ Anxiety scores } & Mean & Md & SDd & SEMd & "t” value \\
\hline pre test & 59.23 & & & & \\
\hline post test & 50.06 & 9.167 & 1.931 & 0.353 & $26^{*}$ \\
\hline
\end{tabular}

* Significant at 0.05 level of significance

$\mathrm{df}=29, \mathrm{t}=2.04$ at 0.05 level of significance

The data presented in table-2 shows that the mean posttest anxiety scores of the experimental group mothers was (50.06) and mean pretest anxiety scores was (59.23) with as mean difference of 9.167, which was found to be statistically significant as evident from 't' value of 26 for df 29 at 0.05 level of significance. This shows that the obtained mean difference between the pretest and the posttest anxiety score was a true difference and not by chance. So the research hypothesis $\left(\mathbf{H}_{1}\right)$ was accepted. This indicates that the anxiety level of the experimental group mother was significantly reduced in the posttest. Thus it can be inferred that the music therapy was effective in reducing the anxiety level of the primipara mothers in first stage of labour.

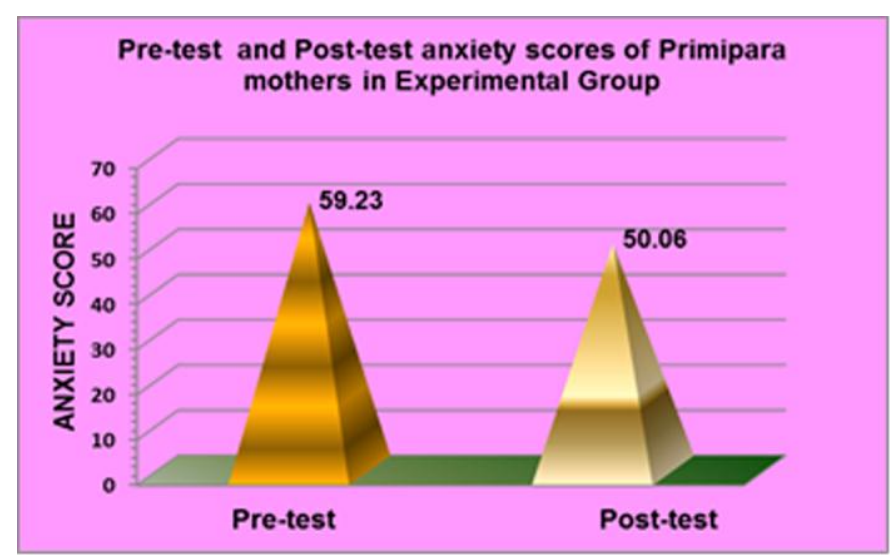

Figure 3: Pyramidal graph showing pre-test and post-test anxiety scores of the primipara mothers in experimental group.

\section{Section IV}

1. Findings related to the evaluation of effectiveness of music therapy in terms of pain perception of primipara mothers during the first stage of labour 
TABLE-3: Mean, Median, Standard Deviation and Range of Score of the Pretest and Posttest Pain Perception Scores of Primipara mothers in experimental group

\begin{tabular}{|c|c|c|c|c|c|c|c|c|}
\hline \multirow[b]{2}{*}{ Group } & \multicolumn{2}{|c|}{ Mean } & \multicolumn{2}{|c|}{ Median } & \multicolumn{2}{|c|}{ Standard Deviation } & \multicolumn{2}{|c|}{ Range of Score } \\
\hline & Pretest & Posttest & Pretest & Posttest & Pretest & Posttest & Pretest & Posttest \\
\hline $\begin{array}{l}\text { Experimental } \\
\text { group } \\
(\mathrm{n}=30)\end{array}$ & 7.8 & 6.27 & 8 & 6 & 0.66 & 0.52 & $5-7$ & $5-7$ \\
\hline
\end{tabular}

The maximum possible score is 10

In order to compare the means of pre-test and post-test pain perception scores of experimental group, ' $t$ ' test was computed. The data is given in table 4.

TABLE-4: Mean, Mean Difference, Standard Deviation Difference, Standard Error of Mean Difference and " $t$ " values of pretest and posttest Pain perception scores of primipara mothers in experimental group

\begin{tabular}{|l|c|c|c|c|c|}
\hline Pain Scores & Mean & Md & SDd & SEMd & "t " value \\
\hline pre test & 7.800 & & & \\
\hline post test & 6.267 & 1.533 & 0.571 & 0.104 \\
\hline Significant at 0.05 level of significance & \\
\hline
\end{tabular}

* Significant at 0.05 level of significance

$\mathrm{df}=29, \mathrm{t}=2.04$ at 0.05 level of significance

The data presented in table 4 shows that the mean post test pain scores of the experimental group mothers was (6.267) and mean pretest pain scores was (7.800) with as mean difference of 1.533 , which was found to be statistically significant as evident from ' $t$ ' value of 14.70 for $\mathrm{df} 29$ at 0.05 level of significance. This shows that the obtained mean difference between the pretest and the posttest pain score was a true difference and not by chance. So the research hypothesis $\left.\mathbf{( H}_{\mathbf{2}}\right)$ was accepted. This indicates that the pain level of the experimental group mothers was significantly reduced in the posttest. Thus it can be inferred that the music therapy was effective in reducing the pain level of the primipara mothers in first stage of labour.

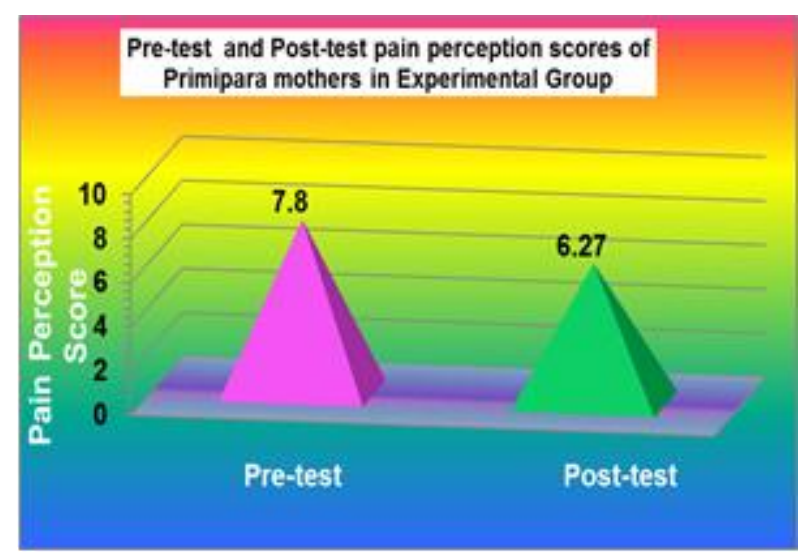

Figure 4: Pyramidal graph showing pre-test and post-test Pain PerceptionScores of the Primipara Mothers in experimental group

\section{SECTION-V}

1. Findings related to the evaluation of effectiveness of music therapy in terms of relationship between post test anxiety level and pain perception scores of primipara mothers during the first stage of labour To find the correlation between the post-test anxiety and post-test pain perception scores of primipara mothers in experimental group, ' $r$ ' value was computed. The data is given in table-6.

TABLE-5: Co-efficient of correlation between anxiety score and pain perception scores of primipara mothers in experimental group

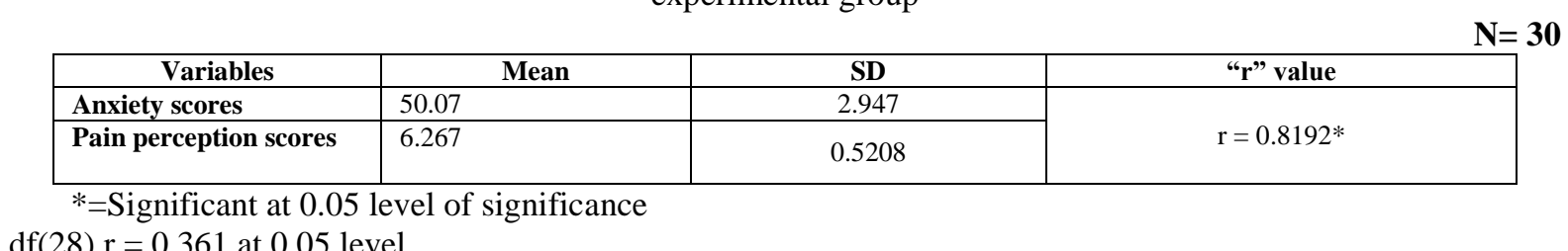


The data presented in table-5 shows that the mean post test anxiety scores in the experimental group mothers was (50.06) with standard deviation of 2.947. The mean posttest pain perception scores was (6.267) with standard deviation of 0.5208 . Numbers of XY pairs (anxiety scores and pain perception scores) in the study were 30. Pearson ' $r$ ' value was found to be 0.8192 which indicated that there was statistically significant correlation between anxiety scores and pain perception scores. So the research hypothesis $\left(\mathbf{H}_{\mathbf{3}}\right)$ was accepted. It was observed that anxiety scores and pain perception scores were having positive correlation in primipara mothers at first stage of labour. The positive correlation shows that as anxiety score decrease, the pain perception scores also reduce in primipara mothers receiving music therapy.

\section{Discussion}

A perfect and safe childbirth process requires appropriate pain management. Intervention of pain and discomfort during labour and childbirth is a major part of evidence based midwifery practice. Relaxation techniques help to keep the mother's body tension free to avoid excessive pain and discomfort. These techniques must be practiced before as well as during labour to effectively manage pain. There are different relaxation techniques that are commonly practiced such as hypnosis, yoga, meditation, walking, massage or counter pressure, changing position, taking a bath or shower, distracting mother by counting or performing an activity that keeps her mind otherwise occupied, among others.

As an age old relaxation technique, proper music is having tremendous positive impact on mind. The findings of the study revealed some interesting facts that music therapy was effective in reducing the anxiety level, pain perception and total duration of labour in primipara primipara mothers during the first stage of labour. This has been supported by some other studies by Tournaire M.,et al. (2010), Liu YH., et al. (2010), Yang, M., et al. (2009), Phumdoung S. and Good M. (2003) and Browning, C.A (2000) that the mothers receiving music therapy group had had significantly less sensation of pain and anxiety and music is an important adjunct in pain and stress management during labor and birth process [3-7].

During labour the mother experiences a high level of anxiety with intense and stressful pain. The same thing was observed in this study. Findings of the present study further indicated that by administering music therapy there was significant reduction in anxiety level and pain perception scores with increasing the mother's ability to cope with labor. Also there was a positive correlation between anxiety level and pain perception scores during first stage of labor in primipara mothers taken in the study. This indicated that decrease in anxiety level could reduce the pain perception of primipara mothers. This has been supported by the study by Cruzik and Jokic-Begic (2011) which revealed that state anxiety correlated significantly with maximum and average labor pain expectancies, whereas trait anxiety correlated significantly with maximum labor pain expectancies [8].

\section{Conclusions}

On the basis of the findings of the present study it can be concluded that

$>$ There was a positive significant relationship between anxiety level and pain perception scores of primipara mothers during first stage of labor. This indicates that decrease in anxiety level could reduce the pain perception of primipara mothers during first stage of labour.

$>$ Mothers exposed to music therapy during labour experienced significantly less anxiety and pain.

Therefore it is speculated that music therapy would be very helpful in alleviating anxiety level and pain perception in primipara mothers during first stage of labour.

\section{Implications of the Study}

The findings of the present study have implications for nursing practice, nursing administration, nursing education and nursing research.

\section{Nursing practice}

Mothers experience anxiety and pain during the normal delivery process which affects the maternal and fetal outcome.

- An in service education programme can be organized to train the nurses about the use of music therapy during labor.

- Nurses should understand the importance of different nonpharmacological, measures to reduce anxiety and pain of the mothers during labor.

\section{Nursing Administration}

- The nurse administrator needs to organize an in-service education programme for the nurses to teach them about the music therapy and conduct workshops, conferences, and seminars on non-pharmacological methods to reduce labour pain perception. 


\section{Nursing Education}

- The students should be taught in detail about the all non-pharmacological measures to reduce anxiety, pain during labor and improve the maternal and fetal outcome.

- The alternative and complimentary therapies (the music therapy is one of them) can be included in the syllabus of the curriculum of basic nursing programme.

\section{Nursing Research}

$\diamond$ Opportunities to be given for doing research in field of music therapy as well as other relaxation techniques to reduce anxiety and pain of the mothers during labour to improve the labour outcome.

$\diamond$ Emphasis should also be given on publication of findings of these types of researches in various journals. Research findings could also be presented at various nursing forums for developing awareness among nurses.

The limitations of the study were:

\section{Limitations}

- The study was confined to a small number of the primipara mothers that limits the generalization of the findings.

- The study did not include multi para mothers.

- It was not associated with high risk factors with vertex presentation and occipito-anterior position.

\section{Recommendations and Future Perspectives}

On the basis of the findings, the following recommendations are offered for future research:

- The study can be replicated on larger sample in different setting so that the findings can be generalized to larger population.

- A similar study may be done on both primipara and multipara mothers.

- A study can be conducted to assess the effectiveness of other nursing measures such as breathing exercises, warm water bath (Hydrotherapy), TENS, acupuncture, aromatherapy, reflexology, position and labour support for effective pain management during labour.

- The study can be replicated on other kind of patients other than mothers during labor.

- The study of music therapy can be started from the antenatal period and early in labor to help women to respond to their contractions with relaxation and better labour outcome.

- Music therapy can be used by headphones, pillow speakers, in-ear speakers, or "in-room" music, as the mothers prefer.

- A study can be done using music therapy with combination to other relaxation therapy during labour.

\section{Journals}

\section{References}

[1]. Chang, M.Y., C.H. Chen, and K.F. Huang, Effects of music therapy on psychological health of women during pregnancy. Journal of Clinical Nursing, 2008. 17(19): p. 2580-2587.

[2]. Cignacco, E., et al., The efficacy of non-pharmacological interventions in the management of procedural pain in preterm and term neonates. European Journal of Pain, 2007. 11(2): p. 139-152.

[3]. Tournaire, M. and A. Theau-Yonneau, Complementary and alternative approaches to pain relief during labor. Evidence-based Complementary and Alternative Medicine, 2007. 4(4): p. 409-417.

[4]. Liu, Y.H., M.Y. Chang, and C.H. Chen, Effects of music therapy on labour pain and anxiety in Taiwanese first-time mothers. Journal of Clinical Nursing, 2010. 19(7-8): p. 1065-1072.

[5]. Yang, M., et al., Music therapy to relieve anxiety in pregnant women on bedrest: a randomized, controlled trial. MCN: The American Journal of Maternal/Child Nursing, 2009. 34(5): p. 316-323.

[6]. Phumdoung, S. and M. Good, Music reduces sensation and distress of labor pain. Pain Management Nursing, 2003. 4(2): p. 54-61.

[7]. Browning, C.A., Using music during childbirth. Birth, 2000. 27(4): p. 272-276.

[8]. Curzik, D. and N. Jokic-Begic, Anxiety sensitivity and anxiety as correlates of expected, experienced and recalled labor pain. Journal of Psychosomatic Obstetrics \& Gynecology, 2011. 32(4): p. 198-203.

\section{Websites}

[1]. http://www.musictherapy.org/

[2]. http://www.who.org

[3]. http://www.emro.who.int/

[4]. http://whiteribbonalliance.org/

[5]. http://sursanjeevan.com/ 